\title{
ANÁLISE DA SECAGEM DE FOLHAS E HASTES DE HORTELÃ EM SECADOR TIPO CESTO ROTATIVO
}

\author{
A. H. ROSANOVA ${ }^{1 *}$, M. C. FERREIRA ${ }^{2 *}$ \\ ${ }^{1}$ Universidade Federal de São Carlos, Programa de Pós-Graduação em Engenharia Química \\ ${ }^{2}$ Universidade Federal de São Carlos, Departamento de Engenharia Química \\ e-mail: ahrosanova@uol.com.br ${ }^{1}$, mariaf@ufscar.br ${ }^{2}$
}

\begin{abstract}
RESUMO
Os objetivos do presente trabalho foram analisar a secagem de ramos de hortelã comum no secador de cesto rotativo e avaliar, separadamente, as cinéticas de secagem das frações (folhas e hastes), bem como avaliar a influência da quantidade de material e da temperatura do ar na secagem desses materiais. O secador consiste de um cesto cilíndrico metálico com paredes perfuradas, que rotaciona em torno do eixo horizontal. $\mathrm{O}$ ar aquecido é alimentado através das paredes perfuradas, perpendicularmente ao eixo horizontal. Foram realizados experimentos utilizando três temperaturas do ar de secagem $\left(40,50\right.$ e $\left.60{ }^{\circ} \mathrm{C}\right)$, e duas quantidades de material $(500$ e $750 \mathrm{~g}$ de hortelã in natura). Durante a secagem, foram avaliadas as características do material (conteúdo de umidade, cor e temperatura), e as temperaturas da parede do cesto, do ar de secagem e do ambiente. Em todas as condições, a remoção de umidade foi mais rápida e a variação da cor maior para as folhas em relação às hastes, e portanto, é interessante que durante o processo seja feita uma análise separada do comportamento das frações que compõem os ramos. Quanto ao processo, a secagem a $60{ }^{\circ} \mathrm{C}$ foi mais adequada, pois proporcionou boa movimentação do material, a obtenção de ensaios reprodutíveis e um produto final homogêneo, porém, foi a condição que ocasionou maiores alterações na cor do produto.
\end{abstract}

\section{INTRODUÇÃO}

Existe na literatura uma grande quantidade de trabalhos que avaliaram a secagem de plantas, sendo que os que utilizam a configuração de secagem em leitos fixos, tais quais os secadores de estufa e de bandejas, são os mais comuns. Todavia, Lima (2013) observou que para a secagem de plantas, a utilização de leitos fixos pode resultar em um produto final não uniforme, e portanto, sugeriu a necessidade de desenvolvimento de secadores de leitos móveis adequados para a secagem desse tipo de material.

Nesse sentido, baseando-se no princípio de funcionamento dos secadores rotativos convencionais, Rosanova e Ferreira (2014) desenvolveram um secador para a secagem de plantas, o qual foi denominado cesto rotativo, e avaliaram o desempenho do mesmo na secagem de folhas e hastes de hortelã comum.

As autoras avaliaram duas temperaturas do ar $\left(70\right.$ e $\left.80{ }^{\circ} \mathrm{C}\right)$, na secagem de $240 \mathrm{~g}$ de ramos de hortelã in natura. Concluíram que, para as condições avaliadas, o cesto rotativo foi adequado para a secagem de hortelã comum, uma vez que promoveu boa movimentação do material e uma secagem homogênea. Todavia, como a hortelã encolhe consideravelmente, principalmente nas 3 primeiras horas de secagem, foi observado que somente no início do processo o volume útil do cesto foi plenamente utilizado. 
A hortelã é uma das plantas medicinais e aromáticas mais conhecidas e utilizadas, visto que há uma vasta gama de aplicações para ela. Na indústria alimentícia, pode ser empregada em aromatizantes, temperos, chás, etc., e na farmacêutica, para a produção de cosméticos e medicamentos (Doymaz, 2006; Tarhan et al., 2010).

Os ramos de hortelã (Figura 1) são compostos por folhas e hastes, materiais com características distintas tanto em termos químicos (composição, teor de constituintes, etc.), quanto físicos (forma, dimensões, etc.).

Figura 1 - Ramo de hortelã comum.

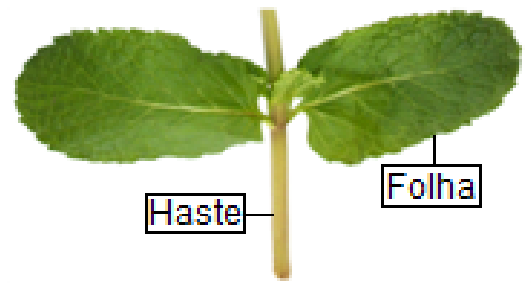

Fonte: Autor (2015).

As diferenças existentes entre folhas e hastes é um complicador para a secagem de plantas inteiras, uma vez que as suas características distintas, implicam em cinéticas de secagem diferentes para cada uma das frações (Tarhan et al., 2010). A maioria dos trabalhos encontrados na literatura, porém, focaram exclusivamente na secagem de folhas das mais diversas espécies vegetais, sendo escassas as informações existentes quanto às hastes (Tarhan et al., 2010). Entretanto, tendo em vista que as hastes são materiais ricos em vitaminas, minerais e fibras, podendo conter até 40 vezes mais nutrientes que a própria folha, a sua utilização no processo é interessante (Bueno, 2013).

Assim sendo, visando dar continuidade ao desenvolvimento do secador do tipo cesto rotativo, os objetivos do presente trabalho foram analisar a secagem de ramos de hortelã comum, e avaliar, separadamente, as cinéticas de secagem de folhas e hastes, bem como avaliar a influência da massa de material utilizada e da temperatura do ar, na secagem de cada uma das frações.

Para atingir-se os objetivos do trabalho, foi feita inicialmente uma caracterização físico-química das frações, e foram avaliadas as alterações das propriedades do material (redução da umidade, variação da cor e temperatura do material) durante a secagem. Para auxiliar a análise do processo, foram medidas também as temperaturas ambiente e da parede do cesto, em função do tempo, durante o processo de secagem.

\section{MATERIAIS E MÉTODOS}

Os ensaios foram realizados no Centro de Secagem do DEQ-UFSCar, e a hortelã comum (Mentha x villosa Huds) utilizada, foi adquirida no comércio de São Carlos.

Foi feita uma seleção dos ramos de hortelã, visando obter-se amostras saudáveis, e de tamanho e coloração semelhantes, e portanto, reduzir-se a variabilidade natural inerente a esse tipo de material.

Então, as frações (folhas e hastes) do material in natura, foram caracterizadas através da determinação do conteúdo de umidade, pelo método da estufa, e da massa específica aparente, por picnometria líquida com hexano. Ainda, de 90 folhas e 90 hastes, foram medidas as dimensões características, com o auxílio do software Image-Pro Plus, e a esfericidade, pela relação entre a média geométrica dos três eixos perpendiculares e o maior eixo do material (Lima, 2013).

Nos experimentos de secagem, foram avaliadas três temperaturas do ar $(40,50 \mathrm{e}$ $60^{\circ} \mathrm{C}$ ), já que a temperatura é um dos fatores que mais influencia a cinética de secagem e qualidade do material (Rosanova e Ferreira, 2014). Os níveis utilizados foram definidos com base em valores usualmente encontrados na literatura para a secagem de hortelã (Antal et al., 2011; Doymaz, 2006).

Também foram avaliadas duas quantidades de material $(500$ e $750 \mathrm{~g}$ de 
hortelã in natura), definidas de acordo com resultados obtidos em trabalho anterior (Rosanova e Ferreira, 2014).

Todos os ensaios foram realizados em duplicata.

\subsection{Equipamento}

O sistema experimental utilizado (Figura 2) foi desenvolvido no Centro de Secagem do DEQ-UFSCar, tendo como base o princípio de funcionamento dos tambores rotativos convencionais, diferindo destes pelo modo como o ar foi alimentando no sistema (através das paredes do cesto), e pela ausência de suspensores internos (Tarhan et al., 2010).

Figura 2 - Esquema do secador cesto rotativo.

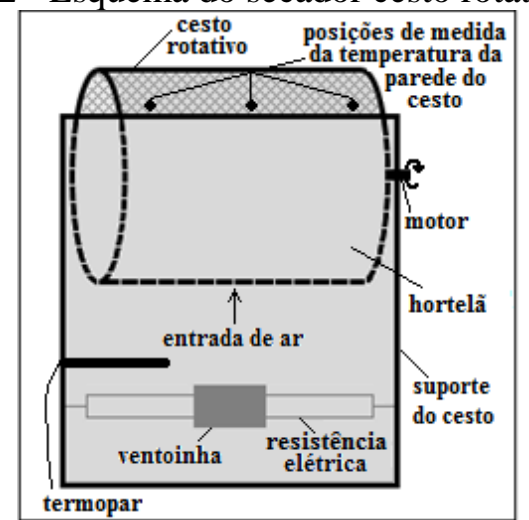

Fonte: Adaptado de Rosanova e Ferreira (2014).

O material a ser seco foi inserido no interior do cesto, o qual possui $26 \mathrm{~cm}$ de comprimento e $14,5 \mathrm{~cm}$ de diâmetro. Ele foi construído com material metálico perfurado, e revestido internamente com uma tela perfurada de pequena abertura, a qual permitiu a passagem do ar para o interior, sem que a hortelã saísse pelos furos.

O cesto foi acoplado a um motor, que lhe proporcionou um movimento rotacional, com velocidade de rotação controlada por um controlador modelo 00/510 da marca Diact. A velocidade do tambor foi mantida em $2 \mathrm{rpm}$ em todos ensaios, pois esta foi a menor velocidade possível no sistema experimental.

A alimentação do ar de secagem se deu com uma ventoinha de baixa potência, a qual foi acoplada à parede lateral da base onde o cesto foi suportado.

Para medir a velocidade do ar no interior do cesto, foi utilizado um kit tri-sense modelo 37000-95 e uma sonda modelo 37000-61 da Cole Parmer. Com o cesto vazio, a sonda foi inserida no seu eixo central, e as medidas realizadas de uma lateral a outra, a cada $2,5 \mathrm{~cm}$ do seu comprimento. Entretanto, não foi possível medir essas velocidades, uma vez que os valores eram muito baixos para serem registrados pela sonda de medida (cujo limite inferior é de $0,51 \mathrm{~m} / \mathrm{s}$ ), mesmo para a máxima velocidade possível da ventoinha. Assim sendo, a velocidade do ar foi mantida constante, na máxima velocidade possível da ventoinha, em todos os ensaios.

Para o aquecimento do ar de secagem, foi utilizada uma resistência elétrica, a qual foi inserida próxima à ventoinha. Um variador de potência da marca Auje modelo M-2412, foi ligado à resistência elétrica, e permitiu fixar-se a temperatura no valor desejado pelo ajuste da potência dissipada.

A temperatura do ar de secagem, medida antes da entrada no cesto, na posição indicada na Figura 2, e do ar ambiente, foram determinadas com o uso de um termopar tipo J da Cole Parmer. As temperaturas do material e da parede do cesto, medidas em três posições axiais do cesto (Figura 2), foram determinadas com o auxílio de um termômetro de infravermelho modelo MT350 da Minipa.

\subsection{Metodologia}

Após a seleção inicial, os ramos de hortelã foram lavados em água corrente, secos superficialmente com papel macio, e cortados em pedaços de tamanho entre 2 e $3 \mathrm{~cm}$.

Os experimentos foram realizados em dois dias. No primeiro dia foi feita a présecagem no cesto rotativo, de dois ou três lotes contendo cerca de $250 \mathrm{~g}$ de ramos de hortelã cada um, durante $3 \mathrm{~h}$, utilizando-se a temperatura pré-estabelecida para a condição 
em estudo. A pré-secagem é interessante, pois uma vez que o encolhimento do material é mais acentuado no início do processo, ela permite um melhor aproveitamento do volume útil do cesto durante todo o processo.

Após a pré-secagem, o material foi armazenado por uma noite ao abrigo de luz, em um vidro hermeticamente fechado. No dia seguinte, a temperatura do ar de secagem foi fixada na mesma utilizada no dia anterior, e então todo o material pré-seco foi inserido no cesto, e o processo de secagem se deu por mais 12 horas.

A cor e o conteúdo de umidade, e as temperaturas do ar de secagem, do ambiente, do material e da parede do cesto foram determinadas antes e após a pré-secagem, no início do segundo dia, a cada 2 horas de processo, e ao fim da secagem. Em todos os instantes de tempo a cor e umidade foram determinadas para frações de folhas e de hastes, separadamente.

Para as medidas de cor, realizadas em triplicata, foram utilizados cerca de $6 \mathrm{~g}$ de material, que posteriormente foi destinado às análises de umidade, um espectrofotômetro modelo CM-5 da marca Konica Minolta, e o sistema de cores CIELAB, o qual expressa a cor em função dos parâmetros $\mathrm{L}^{*}, \mathrm{a}^{*} \mathrm{e} \mathrm{b}^{*}$. Para o cálculo da variação da cor durante o processo $\left(\Delta \mathrm{E}^{*}\right)$ foi utilizada a Equação 1 .

$$
\Delta E^{*}=\sqrt{\left(L_{0}^{*}-L_{t}^{*}\right)^{2}+\left(a_{0}^{*}-a_{t}^{*}\right)^{2}+\left(b_{0}^{*}-b_{t}^{*}\right)^{2}}
$$

onde $\mathrm{o}$ índice 0 corresponde ao valor do parâmetro para o material in natura e o t ao valor em um instante de tempo qualquer.

O conteúdo de umidade de cada uma das frações foi determinado pelo método da estufa $\left(105 \pm 3{ }^{\circ} \mathrm{C}\right.$ durante $\left.24 \mathrm{~h}\right)$. Essa análise foi feita em duplicata, utilizando-se $1 \mathrm{~g}$ de folhas ou hastes para cada medida. Os resultados foram expressos em umidade adimensional, calculada pela razão entre as umidades, em base seca, em um instante de tempo qualquer e inicial.

\section{RESULTADOS E DISCUSSÕES}

Nos itens a seguir, serão apresentados os resultados obtidos na caracterização da hortelã in natura, e nos ensaios de secagem realizados no cesto rotativo.

\subsection{Caracterização do material in natura}

Na Tabela 1, são apresentados os resultados obtidos na caracterização física, realizada para folhas e hastes in natura.

Tabela 1 - Características de folhas e hastes de hortelã comum in natura.

\begin{tabular}{ccc}
\hline & Folhas & Hastes \\
\hline Umidade $(\mathrm{bs})$ & $6 \pm 1$ & $10 \pm 3$ \\
Massa específica & $0,86 \pm 0,02$ & $0,79 \pm 0,01$ \\
aparente $\left(\mathrm{g} / \mathrm{cm}^{3}\right)$ & $0,12 \pm 0,01$ & $0,19 \pm 0,02$ \\
Esfericidade & $0,18 \pm 0,02$ & - \\
Espessura $(\mathrm{mm})$ & - & $2,5 \pm 0,5$ \\
Diâmetro $(\mathrm{mm})$ & $3,5 \pm 0,4$ & - \\
Largura $(\mathrm{cm})$ & $6,1 \pm 0,8$ & $2,4 \pm 0,2$ \\
Comprimento $(\mathrm{cm})$ & $16 \pm 3$ & $0,7 \pm 0,2$ \\
Área projetada $\left(\mathrm{cm}^{2}\right)$ & $33 \pm 7$ & $2,0 \pm 0,5$ \\
Área superficial $\left(\mathrm{cm}^{2}\right)$ & $0,29 \pm 0,07$ & $0,12 \pm 0,06$ \\
\hline Volume $\left(\mathrm{cm}^{3}\right)$ &
\end{tabular}

Fonte: Autor (2015).

Para as hastes, com exceção da massa específica, esfericidade, e comprimento, os desvios obtidos foram expressivos, chegando a $50 \%$ para o volume, $30 \%$ para a umidade e $25 \%$ para a largura. Já para as folhas, os desvios foram significativos somente para o volume (24\%), umidade (16\%) e áreas (20). Portanto, embora as amostras de cada fração apresentem diferenças, o que é esperado, devido a variabilidade natural inerente a materiais biológicos, as diferenças obtidas entre as hastes foram maiores. Isso pode ser explicado pelo fato das características da haste tenderem a variar mais em função da posição em que foi retirada do ramo e do estágio de crescimento do material, em relação à folha. 
Quando comparadas as frações, observa-se que elas possuem características bastante distintas, uma vez que as folhas, as quais possuem geometria plana, apresentaram valores significativamente maiores para as dimensões e área superficial, e menor para o conteúdo de umidade, em relação às hastes, que têm a forma de um cilindro.

\subsection{Ensaios de secagem}

Para avaliar a reprodutibilidade dos ensaios realizados, os dados de umidade adimensional (UM) em função do tempo, para a condição em que foi utilizada a temperatura de $50{ }^{\circ} \mathrm{C}$ e $500 \mathrm{~g}$ de ramos de hortelã, são apresentados, para folhas e hastes, nas Figuras 3 e 4.

Figura 3 - Umidade adimensional de folhas em função do tempo na secagem de $500 \mathrm{~g}$ a $50{ }^{\circ} \mathrm{C}$.

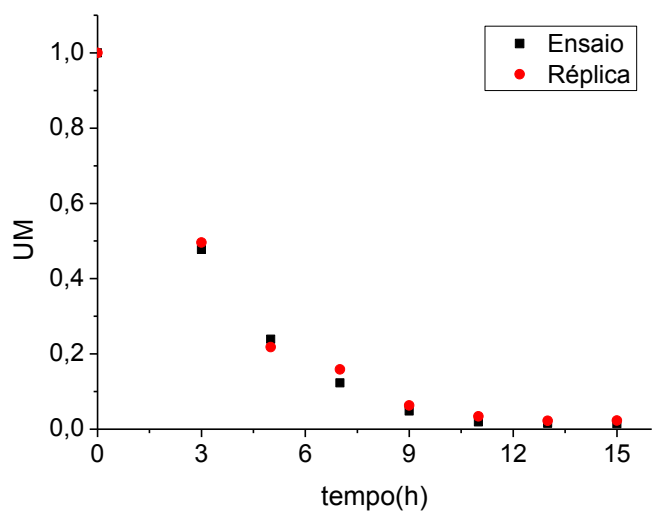

Fonte: Autor (2015).

Figura 4 - Umidade adimensional de hastes em função do tempo na secagem de $500 \mathrm{~g}$ a $50{ }^{\circ} \mathrm{C}$.

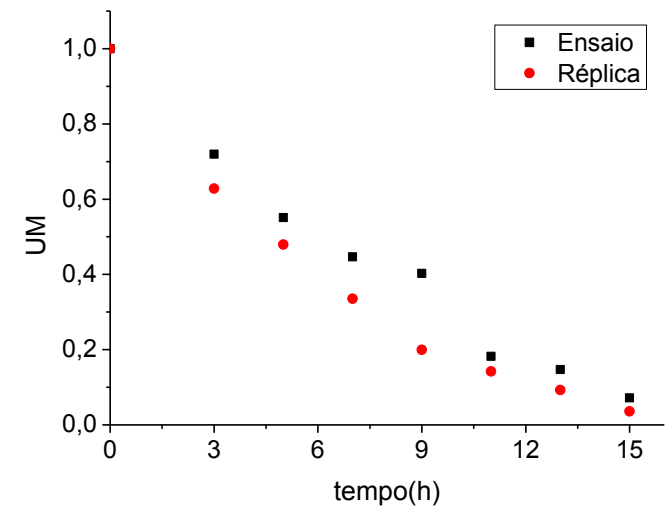

Fonte: Autor (2015).
Os resultados obtidos para ensaio e réplica, para ambas frações, foram próximos, com desvio padrão inferior a 0,03 e 0,15 para folhas e hastes, respectivamente.

Tendo em vista que diversos fatores, tal qual a variabilidade de tamanhos e formas inerente aos materiais biológicos, a dificuldade de seleção de amostras similares para a realização dos ensaios, as variações das condições ambiente, e a utilização de amostras com proporções diferentes de folhas e hastes podem dificultar consideravelmente a reprodutibilidade de experimentos, pode-se considerar que houve uma boa reprodutibilidade dos ensaios.

Esse mesmo comportamento foi observado para as demais condições avaliadas, e portanto, os resultados que serão apresentados a seguir corresponderão à uma média dos valores de ensaio e réplica, obtidos para uma dada temperatura do ar de secagem e quantidade de material.

Para uma comparação dos processos de secagem de cada uma das frações da hortelã, nas Figuras 5 e 6 são apresentados, respectivamente, os dados de umidade e taxa de secagem das frações, em função do tempo de secagem, no ensaio em que utilizou-se $500 \mathrm{~g}$ de material e temperatura do ar de 40 ${ }^{\circ} \mathrm{C}$.

Figura 5 - Umidade adimensional das frações em função do tempo na secagem de $500 \mathrm{~g}$ a $40^{\circ} \mathrm{C}$.

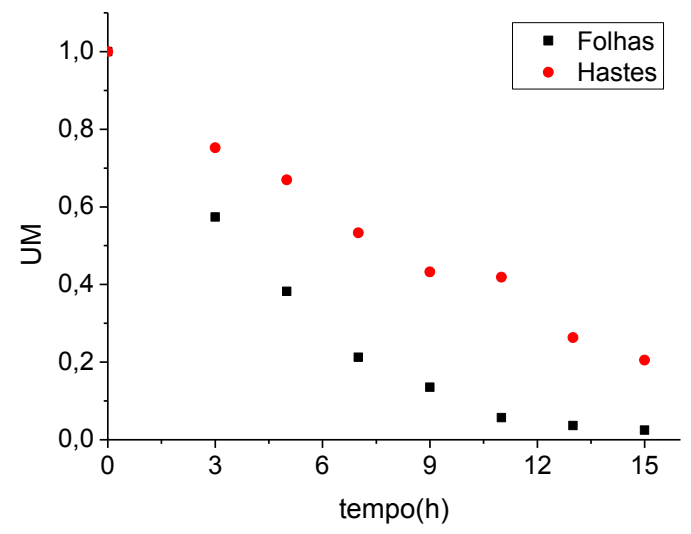

Fonte: Autor (2015). 
Figura 6 - Taxa de secagem das frações em função do tempo na condição de $500 \mathrm{~g}$ e $40{ }^{\circ} \mathrm{C}$.

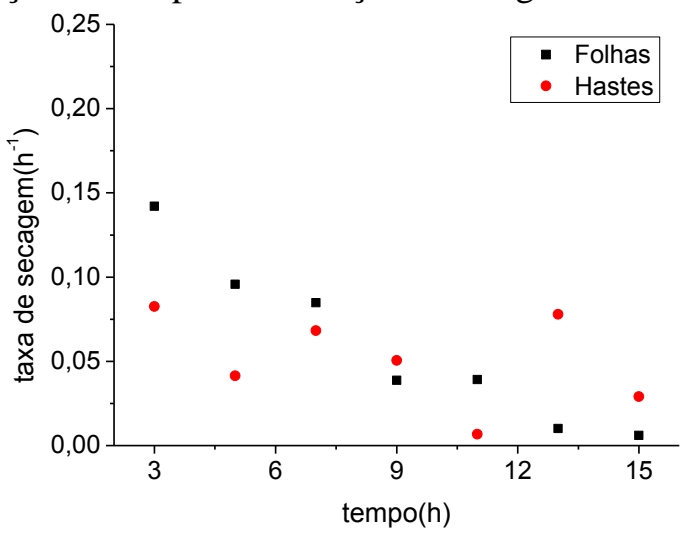

Fonte: Autor (2015).

$\mathrm{Na}$ Figura 5, observa-se que a cinética de secagem foi diferente para cada fração. Enquanto para as folhas, a redução mais expressiva da umidade se deu até cerca de 11 horas de processo, instante de tempo em que a umidade do material $(0,06)$ tendeu a 0 , para as hastes, após 15 horas, o material ainda apresentou alto conteúdo de umidade $(0,20)$.

Assim sendo, para a condição em análise, o equipamento não proporcionou a obtenção de um produto final homogêneo, visto que após 15 horas de secagem, a umidade obtida para as hastes foi significativamente superior à das folhas.

Na Figura 6, observa-se que para ambas frações, o processo ocorreu no período de taxa decrescente, o que está de acordo com o esperado, visto que para materiais agrícolas e alimentos, quase sempre este é o único período observado na secagem (Park, Yado e Brod, 2001). Tal comportamento indica que o transporte de massa é controlado pela resistência interna ao transporte de umidade, ou seja, a difusão é o mecanismo limitante. Ainda, observou-se que para as folhas, até 11 horas, a taxa de secagem foi maior que a das hastes, e a partir de então, ela permaneceu menor e próxima de 0 , já que após 11 horas, a umidade adimensional das folhas tendeu a 0 .

Considerando os valores médios das dimensões medidas para folhas e hastes, a resistência difusiva seria caracterizada pela razão entre a dimensão característica, dada pela razão entre o volume e a área superficial do material, a qual é igual a $8,8 \cdot 10^{-3} \mathrm{~cm}$ para as folhas, e $6.10^{-2} \mathrm{~cm}$ para as hastes, e a difusividade efetiva do material. Portanto, na hipótese que tenham difusividades efetivas similares, estima-se que a resistência interna ao transporte de umidade nas folhas seria cerca de 7 vezes menor que nas hastes, o que contribui para uma secagem mais rápida das folhas.

Adicionalmente, $\mathrm{o}$ fato da área superficial das folhas ser cerca de 16 vezes superior à das hastes, também contribui para a secagem mais rápida das folhas, uma vez que uma maior área superficial aumenta o contato sólido-ar, e portanto, favorece a secagem. Outro fator que contribui para que a secagem ocorra a taxas distintas, é a composição de cada fração, que resulta em diferentes formas de água ligada.

Com a finalidade de comparar a secagem das frações à temperatura de $40{ }^{\circ} \mathrm{C}$, com a condição a $60{ }^{\circ} \mathrm{C}$, os dados de umidade adimensional em função do tempo, para essa condição, são apresentados na Figura 7.

Figura 7 - Umidade adimensional das frações em função do tempo na secagem de $500 \mathrm{~g}$ a $60{ }^{\circ} \mathrm{C}$.

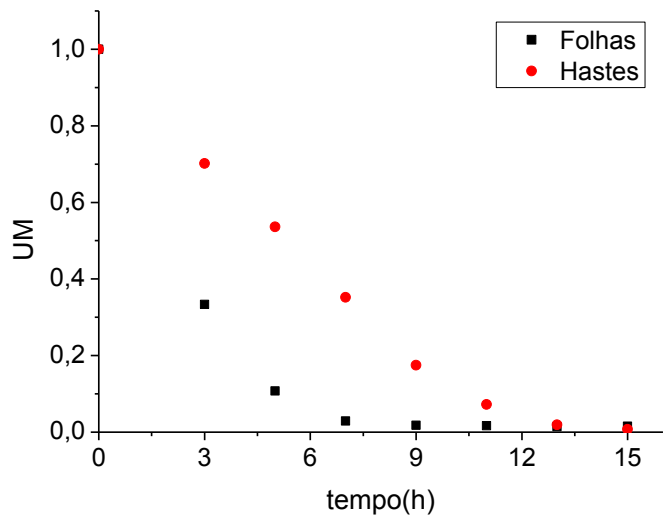

Fonte: Autor (2015).

$\mathrm{Na}$ secagem realizada a $60{ }^{\circ} \mathrm{C}$, para ambas frações, as taxas de secagem foram maiores em relação à condição de $40{ }^{\circ} \mathrm{C}$, visto que a umidade de folhas e hastes tenderam a 0 após 7 e 13 horas de processo, 
respectivamente, enquanto que para $40{ }^{\circ} \mathrm{C}$, essa tendência foi observada apenas após 11 horas para as folhas, e para as hastes não foi observada. Portanto, diferentemente da condição anterior, a secagem de $500 \mathrm{~g}$ de hortelã no cesto rotativo à temperatura de 60 ${ }^{\circ} \mathrm{C}$, proporcionou a obtenção de um produto final homogêneo quanto à umidade das frações, visto que ao fim do processo, a umidade das folhas $(0,01)$, foi semelhante à obtida para as hastes $(0,03)$.

Para os ensaios realizados com $750 \mathrm{~g}$ de material nas temperaturas de 40 e $60{ }^{\circ} \mathrm{C}$, os resultados obtidos foram similares aos apresentados para $500 \mathrm{~g}$.

Nas secagens a $50{ }^{\circ} \mathrm{C}$, ambas frações apresentaram comportamentos semelhantes aos obtidos para as demais temperaturas, com cinéticas e taxas de secagem apresentando valores intermediários aos obtidos para $40 \mathrm{e}$ $60{ }^{\circ} \mathrm{C}$. Ainda, para $50{ }^{\circ} \mathrm{C}$, após 15 horas de secagem, não obteve-se um produto homogêneo, uma vez que a umidade final das hastes $(0,10$, em média) foi muito superior à das folhas $(0,02$, em média).

Para avaliar a influência que a quantidade de material utilizada exerce na secagem, nas Figuras 8 e 9, são apresentados para folhas e hastes, respectivamente, os dados de umidade adimensional em função do tempo, nas secagens realizadas a $40{ }^{\circ} \mathrm{C}$.

Para ambas frações, foi observada uma pequena diferença entre as umidades obtidas nos ensaios realizados com as diferentes quantidades de material, de modo que em todos os instantes de tempo, a umidade para $750 \mathrm{~g}$ foi superior a para $500 \mathrm{~g}$. Assim sendo, é possível afirmar que houve pequena influência da quantidade de material utilizada na cinética de secagem, quando secou-se a hortelã com ar à temperatura de $40{ }^{\circ} \mathrm{C}$, embora ao final da secagem, as diferenças na umidade da folha, em particular, tenha sido desprezível.

Uma explicação plausível para os resultados observados é que a energia fornecida ao sistema tenha sido um fator limitante quando a massa de material aumentou de 500 para $750 \mathrm{~g}$, já que além da baixa temperatura do ar de secagem, foi utilizada uma baixa velocidade do ar (inferior a $0,51 \mathrm{~m} / \mathrm{s}$ ) nos experimentos. Isso pode explicar a cinética de secagem um pouco mais lenta quando uma maior quantidade de material foi utilizada. De fato, observou-se que a temperatura do material na condição de $500 \mathrm{~g}\left(30,8{ }^{\circ} \mathrm{C}\right.$, em média), foi levemente superior à de $750 \mathrm{~g}\left(28,3^{\circ} \mathrm{C}\right.$, em média).

Figura 8 - Umidade adimensional de folhas em função do tempo na secagem a $40{ }^{\circ} \mathrm{C}$.

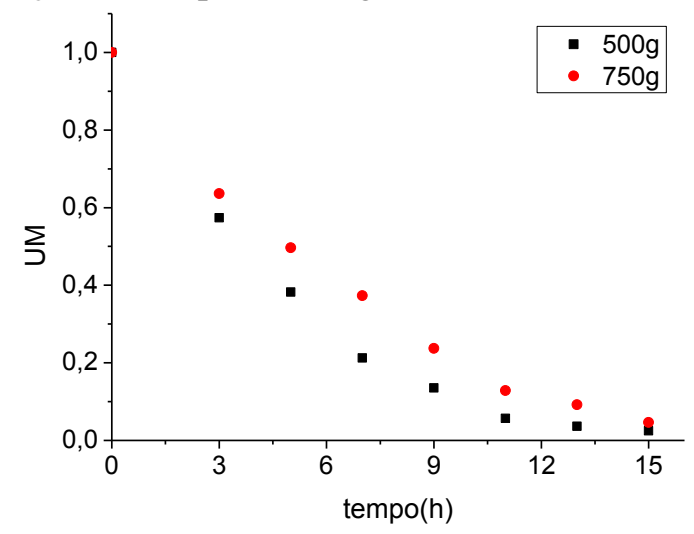

Fonte: Autor (2015).

Figura 9 - Umidade adimensional de hastes em função do tempo na secagem a $40{ }^{\circ} \mathrm{C}$.

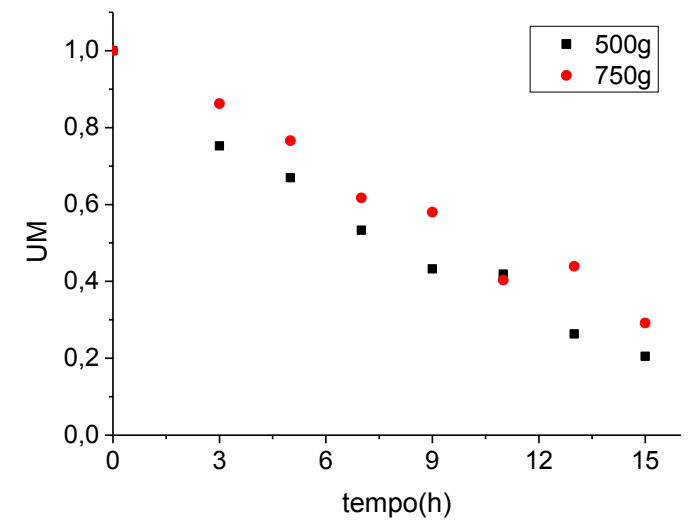

Fonte: Autor (2015).

Já para folhas, na temperatura de $50{ }^{\circ} \mathrm{C}$ (Figura 10), não foi observada uma influência da massa de material. Este resultado está de acordo com o esperado, pois o cesto rotativo 
foi desenvolvido com a finalidade de obter-se um secador que proporcione uma boa mistura do material, e um bom contato entre o ar de secagem e o material. Esse comportamento também foi obtido para a secagem das hastes a $50{ }^{\circ} \mathrm{C}$, e para ambas frações a $60{ }^{\circ} \mathrm{C}$.

Figura 10 - Umidade adimensional de folhas em função do tempo na secagem a $50{ }^{\circ} \mathrm{C}$.

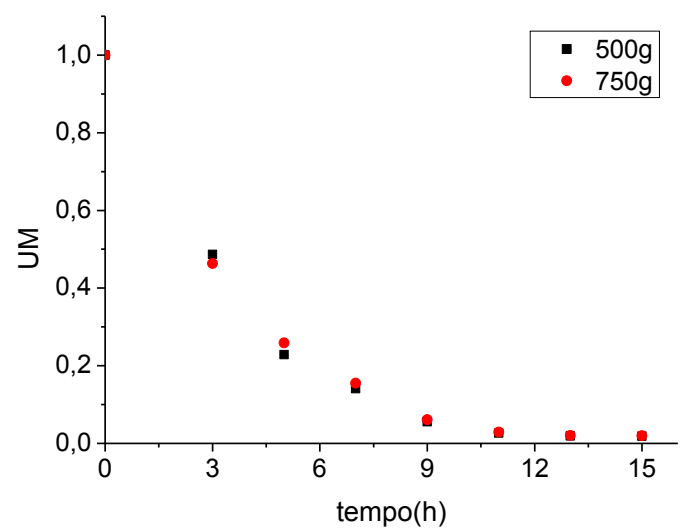

Fonte: Autor (2015).

Para a análise da influência da temperatura do ar na cinética de secagem das frações, são apresentados os dados de umidade adimensional em função do tempo, para folhas (Figura 11) e hastes (Figura 12).

Para ambas frações, foi observado um efeito da temperatura quando utilizou-se ar a $40{ }^{\circ} \mathrm{C}$. Já os resultados obtidos a 50 e $60{ }^{\circ} \mathrm{C}$ mostram que o aumento da temperatura influenciou pouco o processo.

Isso pode ter ocorrido, pelo fato de que, nos ensaios realizados a $40{ }^{\circ} \mathrm{C}$, a temperatura do material, que variou entre 27,2 e $34,0{ }^{\circ} \mathrm{C}$, foi baixa e próxima à temperatura do ar de secagem durante todo o processo. Assim sendo, as diferenças de temperatura entre as fases foram pequenas e, portanto, as taxas de transferência de calor e massa são baixas.

Os resultados similares observados para as temperaturas de 50 e $60{ }^{\circ} \mathrm{C}$, podem ter ocorrido pelo fato de o secador não possuir isolamento térmico. Em razão disto, nem toda a energia do ar aquecido é efetivamente utilizada na secagem, pois parte dela é dissipada para aquecer as paredes do equipamento e para o ambiente. As perdas tendem a ser maiores em uma temperatura maior, uma vez que a temperatura ambiente não variou expressivamente entre os ensaios (variação inferior a 3\%, em termos absolutos). De fato, para os ensaios realizados a $50{ }^{\circ} \mathrm{C}$, a diferença entre as temperaturas da parede do cesto e ambiente chegaram a $15,3{ }^{\circ} \mathrm{C}$, enquanto que para os realizados a $60{ }^{\circ} \mathrm{C}$, as diferenças foram superiores durante todo o processo, chegando a até $20,0{ }^{\circ} \mathrm{C}$, e portanto, as perdas para o ambiente foram maiores quando a maior temperatura foi utilizada.

Para os ensaios realizados com 500g, os resultados foram semelhantes aos para $750 \mathrm{~g}$.

Figura 11 - Umidade adimensional de folhas em função do tempo na secagem de $750 \mathrm{~g}$ de hortelã.

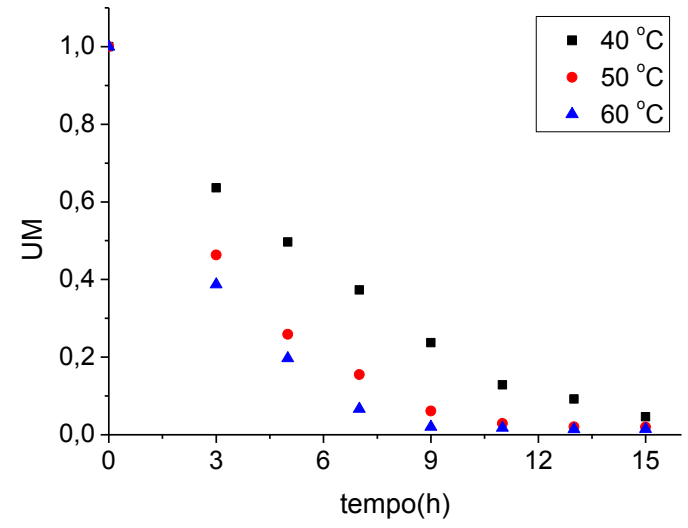

Fonte: Autor (2015).

Figura 12 - Umidade adimensional de hastes em função do tempo na secagem de $750 \mathrm{~g}$ de hortelã.

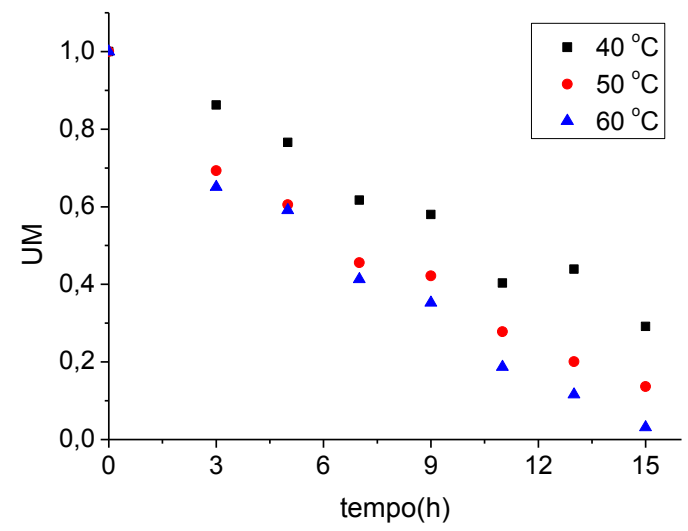

Fonte: Autor (2015). 
Para a avaliação da influência da temperatura na variação da cor do material, os dados para folhas (Figura 13) e hastes (Figura 14) são apresentados a seguir. Para cada temperatura, os resultados correspondem a uma média de 4 valores, obtidos de ensaio e réplica, com 500 e $750 \mathrm{~g}$ de material.

Figura 13 - Variação da cor de folhas em função do tempo para as três temperaturas avaliadas.

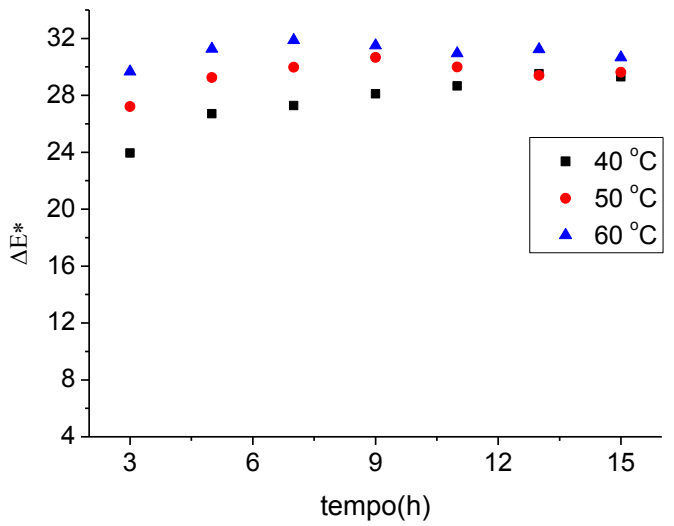

Fonte: Autor (2015).

Figura 14 - Variação da cor de hastes em função do tempo para as três temperaturas avaliadas.

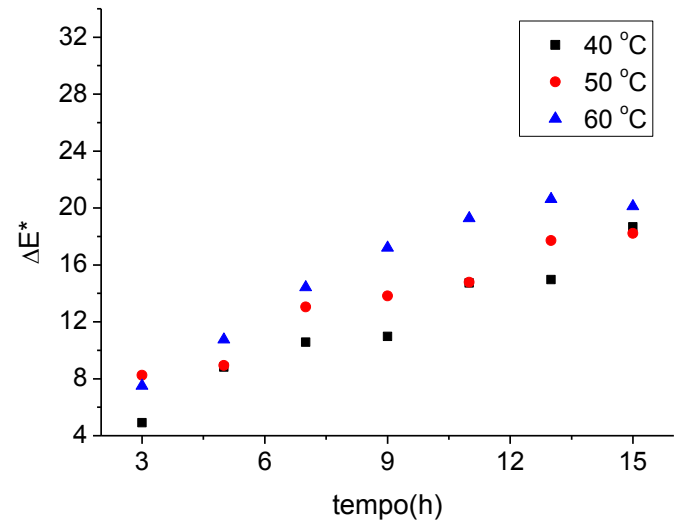

Fonte: Autor (2015).

Para todas as temperaturas, a variação da cor das folhas ocorreu majoritariamente no início da secagem (até cerca de 7 horas), e a partir de então, variou pouco até o fim do processo. Já para as hastes, a variação apresentou tendência de aumento com $\mathrm{o}$ avanço do tempo de secagem.

Para ambas frações, observou-se uma influência da temperatura na variação da cor, sendo que quanto maior a temperatura utilizada, maior foi a variação da cor das frações. Esse resultado está de acordo com o esperado, uma vez que a cor de plantas é dada pela presença de nutrientes e pigmentos, e em temperaturas mais altas, as reações químicas de degradação desses constituintes tendem a ser mais intensas (Buchaillot, Caffin e Bhandari, 2009).

Tendo em vista que a cor é importante para a aceitação comercial do produto seco, e que nas condições avaliadas, a sua variação foi maior nos ensaios a $60{ }^{\circ} \mathrm{C}$, quanto à cor, a secagem a essa temperatura seria menos vantajosa, pois levou à obtenção de um produto final com características mais diferentes em relação às do material in natura.

Após 15 horas de processo, a variação da cor das folhas $(29,14$, em média) foi significativamente superior à das hastes (20,31, em média). Portanto, em todas as temperaturas, o processo de secagem afetou mais a cor das folhas do que a das hastes.

Entretanto, tendo em vista que, após 15 horas, as umidades das hastes submetidas à secagem a 40 e $50 \quad{ }^{\circ} \mathrm{C}$ ainda eram relativamente altas (iguais a 2,7 e 1,2, em base seca, respectivamente), se a intenção for armazenar o produto final, seria necessário um tempo adicional de secagem, até que o conteúdo de umidade dessa porção atinja um valor adequado para esse fim. Uma vez que a variação da cor das hastes tende a aumentar com o avanço da secagem, enquanto que a das folhas tende a permanecer constante após o início do processo, é possível que a variação da cor das hastes se iguale ou até mesmo ultrapasse a das folhas se sua secagem for conduzida até o final.

Embora a cor seja uma análise rápida indicativa de qualidade, a avaliação do efeito da temperatura na qualidade do material precisa ser realizada pela da análise de outras características, como teor e composição de óleos essenciais, e teores de polifenóis e flavonóides. 


\section{CONCLUSÕES}

Com base nos resultados apresentados, conclui-se que na secagem de hortelã no cesto rotativo, as folhas secam mais rapidamente que as hastes, sendo que na condição em que foi utilizada a temperatura de $60{ }^{\circ} \mathrm{C}$, a secagem das folhas foi cerca de $53 \%$ mais rápida que a das hastes. A temperatura afetou a variação da cor de ambas frações, entretanto as folhas apresentaram maiores alterações em relação às hastes. Assim sendo, a análise separada das características de cada fração que compõem os ramos de hortelã na secagem é interessante, visto que se fosse feita para os ramos inteiros, os valores corresponderiam a uma média das frações, o que não descreveria efetivamente o que acontece no processo.

Dentre as condições avaliadas, a utilização do cesto rotativo foi mais adequada para a secagem da hortelã à $60{ }^{\circ} \mathrm{C}$, pois proporcionou boa movimentação do material, ensaios reprodutíveis e a obtenção de um produto final homogêneo, na secagem de 750 $\mathrm{g}$ de material. Por outro lado, nessa temperatura, foram observadas alterações levemente maiores na cor de folhas e hastes, indicando uma maior deterioração na qualidade do material em relação às demais condições. Para as temperaturas de 40 e 50 ${ }^{\circ} \mathrm{C}$, o produto final obtido não foi homogêneo.

$\mathrm{O}$ cesto rotativo é um equipamento em desenvolvimento, e portanto os resultados apresentados neste trabalho são preliminares. Embora haja evidências de que na secagem de hortelã no cesto rotativo, o transporte de massa é controlado pela resistência interna ao transporte de umidade, são necessários estudos adicionais em que se avalie a influência da velocidade do ar, e também de outras variáveis de processo, na secagem e qualidade do produto.

\section{REFERÊNCIAS}

ANTAL, T.; FIGIEL, A.; KEREKES, B.; SIKOLYA, L. Effect of drying methods on the quality of the essential oil of spearmint leaves (Mentha spicata L.). Drying Technology, v.29, p.1836-1844, 2011.

BUCHAILLOT, A.; CAFFIN, N.; BHANDARI, B. Dying of lemon myrtle (Backhousia citriodora) leaves: Retention of volatiles and color. Drying Technology, v. 27, p. 445-450, 2009.

BUENO, C. Casca, talo e sementes são ingredientes saudáveis e gostosos; veja como usá-los. São Paulo, SP, maio/2013. Disponível em: <http://noticias.uol.com.br/>. Acesso em: 26/03/2015.

DOYMAZ, I. Thin-layer drying behaviour of mint leaves. Journal of Food Engineering, v.74, p.370-375, 2006.

LIMA, R.A.B. Análise da secagem convectiva de folhas de manjericão (Ocimum basilicum L.). Tese (Doutorado em Eng. Química), UFSCar, São Carlos, 2013.

PARK, K. J.; YADO,M. K. M.; BROD, F. P. R. Estudo da secagem de pêra bartlett (Pyrus sp.) em fatias. Ciência e Tecnologia de Alimentos, v.23, p.288-292, 2001.

ROSANOVA, A.H.; FERREIRA. M.C. Secagem de hortelã em secador de cesto rotativo. In: Congresso Brasileiro de Engenharia Química, 2014, Florianópolis. Anais... Florianópolis, UFSC, 2014, p.1-8.

TARHAN, S.; TELCI, I.; TUNCAY, M. T.; POLATCI, H. Product quality and energy consumption when drying peppermint by rotary drum dryer. Industrial Crops and Products, v.32, p.420-427, 2010.

\section{AGRADECIMENTOS}

Ao CNPq, CAPES e PPGEQ-UFSCar pelo auxílio financeiro. 